\title{
Research on Cultural Factors in College English Teaching
}

\author{
Guo Liping \\ Foreign Language Research Center, Shaanxi Academy of Governance, 710068
}

Keywords: College English Teaching; Cultural Factors; Bilingual Culture

Abstract: Based on the relationship between language and culture, this paper makes a brief study on the cultural factors in college English teaching. It points out some people's one-sided understanding of English teaching and analyzes the connection between English teaching and Chinese and Western cultural factors. Besides, for the problems of cultural teaching exposed in the traditional English teaching mode, corresponding solutions are put forward to offer useful reference for the innovation of English teaching in colleges and universities.

\section{Introduction}

With the development of economy and society, especially under the influence of globalization, English has become a dominant language for international communication. However, there are still some narrow senses for English. Some people think that English is a tool, and its main role is to convey information. Some people think that English is a branch of knowledge, and it is composed of different knowledge points. Some people think that English is only a typical representative of western languages. These views are one-sided and not objective, ignoring the cultural factors.

Language and culture are inextricably intertwined. Language is an important carrier of culture; and culture has a constraining effect on language. The language that is separated from culture has no connotation. At the same time, without language, culture also lacks a very important inheritance tool. The history of human development is the history of the interaction between language and culture.

When studying English, we should have a clear and comprehensive understanding of English teaching. English teaching and cultural teaching are complementary. Regrettably, one of the drawbacks of college English teaching in China is that only English language knowledge is taught, and there is no deep analysis and interpretation of the cultural factors contained in English teaching.

\section{The Connection Between English Teaching and Culltural Factors}

\subsection{The Connection between English Teaching and English Cultural Factors}

As we all know, the purpose of our English learning is mainly for cross-cultural communication. The "College English Teaching Guide" mentions that the goal of college English teaching is to cultivate students' English application ability and to enhance their cross-cultural communication 
awareness and skills. At the same time, it aims to develop students' self-learning ability and comprehensive cultural accomplishments. From the guide we can see that cultural learning should be synchronized with the learning of English knowledge. But for a long time, the above teaching aim has not been well implemented. English is a complex collection, and it is the representative and embodiment of English culture. It is not a simple accumulation of knowledge, but a scientific system composed of culture, knowledge points, and educational methods. At present, the lack of cultural factors in college English teaching in China leads students to acquire only theoretical knowledge. As a result, students' English application ability has not been effectively improved. Some students cannot recognize and cope with cross-cultural conflicts in international communications.

English cultural factors play a huge role in leading and promoting English teaching. Only by deepening into the study of English culture can we understand the context of English, feel the language connotation of English, and appreciate the unique humanistic charm of English.

\subsection{The Connection Between English Teaching and Chinese Traditional Cultural Factors}

We should consider the social environment related to teaching because English teaching is not a simple and isolated existence. For English teaching, there have been two different opinions in China. On the one hand, people think that English is a representative of western culture and plays an active role in international affairs; therefore, we should vigorously promote and popularize it. Some scholars even believe that English learners should get prepared at lower ages. And many English learning tutoring classes for children have sprung up. However, this initiative has not been officially recognized, and official attitudes have been more cautious. On the other hand, some people believe that English teaching requirements should be appropriate for different students. For English majors, intensive English learning is necessary. But for non-English majors, there is no need to increase the popularity of English. People are worried that the popularity and in-depth promotion of English will have a strong impact on our culture. Especially for young students, their cultural cognition is not mature, and their world outlooks and values on life are both in the formation stage. Excessive English learning and the involvement of English culture will negatively affect students' enthusiasm for learning Chinese traditional culture. In fact, traditional Chinese culture has always been known for its tolerance. However, since modern times, we have been invaded and this history has become a permanent pain in the hearts of Chinese people. Therefore, many people are very wary of foreign cultures. In recent years, although some changes have occurred, people's vigilance has not been completely eliminated . Many experts and scholars have conducted in-depth research and practice on how to deal with the relationship between Chinese and western cultures in teaching. Many experts believe that the teaching of Chinese traditional culture should be appropriately introduced in English teaching. The two ones are not incompatible with each other, but can be inclusive and mutually reinforcing. Only by profoundly understanding the differences in cultures and in thinking between the Chinese and western languages can we use English language more effectively. For example, in English teaching we can introduce the translation of Chinese classical poetry, festival folklore and tea culture, etc., making students feel the charm of Chinese traditional culture while learning English. Such a fusion of Chinese and western cultures is both an exploration and an attempt in English teaching.

\section{Problems and Solutions in English Culture Teaching}

\subsection{Insufficient Teacher Abilities and the Solutions}

Teachers are the organizers and implementers of curriculums. Teachers' abilities and qualities 
will directly affect the education and teaching. Under the traditional education and teaching mode in our country, teachers are in a dominant position, which seems to be a matter of course. It is in this mode that teachers' bilingual culture accomplishments determines the effect of English culture teaching. But unfortunately, the bilingual culture accomplishments of most Chinese teachers are generally not satisfactory. To understand a certain culture, you should really experience it. According to some statistics, only a small number of teachers engaged in English culture teaching in China have experiences of studying abroad and have truly perceived English culture. The way most teachers learn English culture is very simple. They only collect relevant texts and picture materials, attend some English culture courses, or participate in some cultural training. Through this simple training mode it is difficult to create a learned and informed cultural educator. How many college English teachers are really proficient at both Chinese and western cultures? Moreover, in china's universities and colleges teachers have many administrative affairs to cope with; they have little time and energy to continue their studies. Consequently, most teachers' abilities have never been improved. Culture development is a dynamic course. Many teachers do not seek teaching innovations, so the teaching content in class seems to be cliches for students who are eager to accept new things. Over time, students and teachers both feel boring in class.

The lack of teachers' abilities has become one of the biggest obstacles in the development of higher education in China. At present, the seriousness of this problem has been paid more and more attention, and the re-education and retraining of teachers in colleges and universities is also constantly being strengthened. Many key universities sponsored by Project 985 and Project 211 have taken the improvement of teachers' abilities as an important indicator of the school's annual work. However, due to insufficient funding and other reasons, this problem has not been effectively resolved in other ordinary universities and colleges. The improvement of teachers' abilities is a long-term process, which requires strict standards and systems. I believe that in the near future, this issue will be effectively solved under the joint efforts of society and education sectors.

\subsection{Lack of Motivation in Cultural Learning and the Solutions}

In China, the traditional higher education has made great achievements after years of development. However, many inherent modes have been unable to meet the requirements of the development of the times, and even have become obstacles to the reform of English education in colleges and universities. Under the traditional education mode of our country, the explanation of English knowledge points is generally simple, teachers and students rarely discuss cultural phenomena implied by certain knowledge points. Therefore, in the eyes of many students, cultural learning does not help much in their study. As they will not go abroad in the future, learning English culture does not have realistic meaning for them. When teachers introduce knowledge about culture in English teaching activities, they only follow the textbook, and rarely compare the similarities and differences between Chinese and foreign cultures. Students sometimes may feel the difference between the two cultures, but they can not understand the difference well, so they have no objective and rational comparison between the two cultures. At the same time, due to the constraints of our teaching mode, students rarely have the opportunity to experience the real atmosphere of foreign cultures. Over time, students either fully accept or completely reject foreign cultures, and then form one-sided views on cultures. It has been a long time since English culture courses were set up in higher education in China, but how many students can have a comprehensive understanding of English culture through classroom teaching? how many students have improved their intercultural communication accomplishments through English learning? This is not a simple teaching issue, but a complex social issue. This issue involves the concepts and methods of education and teaching, the attitudes of society to foreign cultures, and the objectives of education and teaching. It is precisely 
because of the above various factors that schools and society have maintained an ambivalent attitude to teaching and learning of English culture, and the enthusiasm and initiative of students to study English culture is not high.

Schools and teachers should be good leaders in teaching, making students understand that English culture is very important and serves as a driving force in English learning. Currently, we can learn a lot from other countries' research and practice in this field. At present, some countries have adopted an interdisciplinary approach to the study of foreign language culture, putting cultural learning and language learning at the same level. That is to say, cultural learning is no longer a supplementary subject of language learning, but a juxtaposed and equally important subject. The two disciplines are conducted alternately. Students choose one of the disciplines, and the study of the other discipline should also be included in the assessment system. The English culture learning in China's universities and colleges is still subordinate to English learning. How to do a good job in cultural learning in English teaching is a systematic project. It needs the majority of English educators to make concerted efforts to jointly explore and innovate in theory and practice.

\subsection{Low Proportion of English Course Practice and the Solutions}

English is a practical course, but our English teaching is based on the explanation of knowledge points. The proportion of practice in students' curriculum is very low, and it is difficult for students to have the opportunity to truly apply the cultural knowledge they have acquired, resulting in their low comprehensive language skills.

To solve this problem well, on the one hand, we should strengthen the proportion of English practice classes, and try to create good language practice conditions for students; on the other hand, we should strengthen the construction of training bases. Schools should act as good guides and coordinators, and actively establish relations with relevant employment organizations so that students may be provided with adequate training chances. Then students can demonstrate their comprehensive language skills and cultural literacy during the training. At the same time, we should improve the assessment rules of English learning, formulate scientific and operational English assessment systems; and increase the proportion of cultural course practice in assessment systems, so as to guide students to develop a positive attitude towards cultural learning.

\section{Conclusion}

With the development of China's economy and society, our demand for talents has undergone profound changes. People attach great importance to quality education. How to cultivate high-quality talents to meet the needs of modernization construction is an important task for colleges and universities in China. How to do a good job in English and cultural teaching, making the two ones properly consort with each other is a historical issue for every college English educator.

\section{References}

[1] Fu Xiaoqiu, Zhang Hongling. Intercultural Teaching Design and Implementation of Comprehensive English Course [J]. Foreign Languages, 2017 (1).

[2] Xia Yang, Lin Juan. How to Effectively Improve College Students' Critical Thinking Ability in College English Culture Teaching [J]. Shanxi Youth, 2017 (18).

[3] Hao Min. Discussion on the Necessity of Integrating Chinese Traditional Tea Culture into English Language and Culture Teaching [J]. Fujian Tea, 2017 (2).

[4] Li Hua. Intercultural Education and the Cultivation of Humanities Quality of English Majors [J]. Journal of Higher Education, 2017 (14). 
[5] Cai Yong. Practice of Infiltrating English Culture Education Based on Teaching Materials [J]. English Teachers, 2017 (7).

[6] Wang Xiaojin. Analysis of English Cultural Teaching from the Perspective of Intercultural Communication [J]. Journal of Jiamusi Vocational Institute, 2018(1).

[7] Zhang Qian. Discussion on the Construction of College English Culture [J]. Education and Teaching Forum, 2018 (15).

[8] Knowles G. A Cultural History of the English Language [M]. Beijing: Peking University Press, 2004. 